\title{
Notas e descrições em Bisaltes Thomson, 1868 e Ptericoptus Lepeletier \& Audinet-Serville, 1830 (Coleoptera, Cerambycidae, Lamiinae, Apomecynini)
}

\author{
Maria Helena M. Galileo ${ }^{1,3}$ \\ Ubirajara R. Martins 2,3
}

\begin{abstract}
Aвstract. Notes and descriptions in Bisaltes Thomson, 1868 and Ptericoptus Lepeletier \& Audinet-Serville, 1830 (Coleoptera, Cerambycidae, Lamiinae, Apomecynini).The following new species are described in the subgenus Bisaltes (Bisaltes): B. (B.) picticornis sp. nov. from Bolivia; B.(B.) taua sp. nov. from Brazil (Paraná and Santa Catarina) and B. (B.) unicolor sp. nov. from Ecuador. Bisaltes (B.) pictus Breuning, 1940 is transferred to the subgenus Craspedocerus. In Ptericoptus, $P$. hybridus hybridus Breuning, 1939 is considered a synonym of P. acuminatus (Fabricius, 1801); P. dorsalis Audinet-Serville, 1835 previously in the synonymy of P. acuminatus is revalidated and Saperda vitta Newman, 1838 is considered its synonym; P. corumbaensis sp. nov. is described from Brazil (Mato Grosso do Sul).
\end{abstract}

Keywords. Apomecynini; Bisaltes; Cerambycidae; Lamiinae; Ptericoptus.

\section{INTRODUÇÃO}

A tribo Apomecynini foi revista por BREUnING (1971) e, na chave para os gêneros, Bisaltes Thomson, 1868 e Ptericoptus Lepeletier \& Audinet-Serville, 1830 estão reunidos pela presença de espinho nos lados do protórax e são discriminados pelo escapo com (Bisaltes) ou sem (Ptericoptus) cicatriz apical. Bisaltes foi subdividido em dois subgêneros: sensu stricto e Craspedocerus Aurivillius, 1900. Este subgênero caracterizase pelos antenômeros III a V engrossados. Bisaltes (B.) pictus apresenta os antenômeros III-VII fortemente engrossados e, portanto, deve ser transferido para o subgênero Craspedocerus.

O subgênero Bisaltes, segundo MonNé (1994), conta com 28 espécies ocorrentes na América do Sul. Descrevemos mais três espécies do Equador, da Bolívia e do Brasil.

As espécies do gênero Ptericoptus foram analisadas com base nas descrições e nos diapositivos dos tipos e conseguimos resolver o status de $P$. acuminatus (Fabricius, 1801) e P. dorsalis Audinet-Serville, 1835 e consideramos $P$. h. hybridus Breuning, 1939 sinônima de P. acuminatus. Descrevemos, ainda, uma espécie nova de Corumbá, Mato Grosso do Sul, Brasil.

As siglas mencionadas ao longo do texto correspondem a: BMNH, The Natural History Museum, Londres; CMNH,
Carnegie Museum of Natural History, Pittsburgh; MNHN, Muséum National d' Histoire Naturelle, Paris; MZSP, Museu de Zoologia, Universidade de São Paulo, São Paulo; NHRM, Naturhistoriska Riksmuseet, Estocolmo; USNM, National Museum of Natural History, Washington.

\section{Bisaltes (B.) picticornis sp. nov.} (Fig. 1)

Macho. Tegumento preto. Cabeça revestida por pubescência branco-amarelada exceto numa área occipital que se continua com a faixa central do pronoto. Olhos pequenos; lobos oculares superiores com seis fileiras de omatídios, tão distantes entre si quanto o quíntuplo da largura de um lobo; lobos oculares inferiores nitidamente mais curtos que as genas.

Antenas tão longas quanto o corpo. Escapo, pedicelo e antenômero III revestidos por pubescência esbranquiçada; antenômeros IV, VII e IX pretos, exceto curto anel basal que é esbranquiçado; antenômero V inteiramente preto; antenômeros VI, VIII e X brancos com o ápice preto; antenômero XI com a metade basal branca e a metade apical preta. Flagelômeros basais não-engrossados. Franja, na margem interna, de pêlos tão longos quanto a largura dos antenômeros.

\footnotetext{
1. Museu de Ciências Naturais, Fundação Zoobotânica do Rio Grande do Sul. Caixa Postal 1188, 90001-970 Porto Alegre-RS, Brasil.

2. Museu de Zoologia, Universidade de São Paulo.Caixa Postal 42694, 04299-970 São Paulo-SP, Brasil.

3. Bolsista do CNPq.
} 
Lados do protórax com pequeno tubérculo agudo central. Pronoto com faixa preta, larga, gradual e levemente alargada para a base, que envolve estreitíssima faixa esbranquiçada central. Lados do pronoto, partes laterais do protórax e prosterno revestidos por pilosidade branco-amarelada.

Escutelo preto. Élitros branco-amarelados com uma faixa sutural, da base ao meio, em continuação da faixa pronotal; faixa preta, larga, no terço posterior, oblíqua em sentido descendente da margem para a sutura, que pode ser unicolor ou entremeada por pequenas manchas amarelo-esbranquiçadas; mancha indistinta, amarelo-acastanhada, no quinto apical e que não atinge as pontas.

Pernas amareladas com o lado interno das metatíbias preto. Tarsos recobertos por pubescência esbranquiçada.

Dimensões, em mm, macho. Comprimento do protórax, 2,42,7; maior largura do protórax, 3,2-3,4; comprimento do élitro, 8,9-9,0; largura umeral, 3,7-4,0.

Material-tipo. Holótipo macho, BOLÍVIA, Beni: Uyapi, Guanay, XXI.1992, [Ugarte-Peña col.]. (MZSP). Parátipo macho, BOLÍVIA, Santa Cruz: Provincia del Sara, Acc. 5043, Steinbach col. (CMNH).

Discussão. O padrão de colorido de Bisaltes (B.) picticornis sp. nov. lembra muito os das espécies de Ptericoptus e é único em Bisaltes, com centro do pronoto largamente ocupado por faixa preta larga. As únicas espécies que apresentam essa faixa são B. monticola Tippmann, 1960 e B. adustus (Burmeister, 1865) mas a pubescência corporal, nas duas espécies, é amareloalaranjada, as antenas têm tegumento preto e a metade apical dos élitros é toda preta.

\section{Bisaltes (B.) taua sp. nov.}

(Fig. 2)

Etimologia. Tupi: tauá = amarelo, referente à pilosidade corporal.

Tegumento castanho-escuro ou preto; antenas e pernas com tegumento predominantemente avermelhado.

Cabeça com tegumento preto revestido por pubescência amarelada e algumas áreas no vértice recobertas por pubescência mais alaranjada. Lobos oculares superiores tão distantes entre si quanto o sêxtuplo da largura de um lobo; lobos oculares inferiores tão longos quanto as genas. Escapo recoberto por densa pubescência amarelada, às vezes, com áreas mais alaranjadas. Antenômero III com pubescência inteiramente amarelada e, na base, com estreito anel de pubescência branca. Antenômero IV como o precedente, mas com o ápice mais escuro. Antenômeros V, VII e IX castanhos com a base anelada de branco; VI, VIII, X e XI brancos com o ápice castanho.

Protórax com tegumento preto revestido por pilosidade amarelada, variegada por áreas de pubescência alaranjada; a pubescência relativamente longa e densa, constitui (20 x) alguns pincéis curtos. Lados do protórax e prosterno revestidos por pubescência amarelo-esbranquiçada.

Élitros com tegumento preto ao longo da sutura ou quase inteiramente preto; uma faixa de pubescência esbranquiçada, larga, oblíqua em sentido descendente da margem para a sutura, na metade anterior, que vai desde quase o úmero até a sutura; metade apical com pubescência amarelo-alaranjada, relativamente alongada, constitui áreas irregulares que, nas partes menos densas, permite ver algo do tegumento; quarto apical com duas faixas mais ou menos transversais: uma préapical esbranquiçada e uma apical alaranjada.

Pernas revestidas por pubescência branca, marmoreada de pubescência castanho-avermelhada.

Lados do metasterno revestidos por pubescência amareloalaranjada muito densa. Primeiro urosternito com pubescência amarelo-alaranjada; lados dos urosternitos com pequenas manchas pretas.

Dimensões, em mm, respectivamente macho/fêmea. Comprimento do protórax, 1,9/2,3-2,5; maior largura do protórax, 2,6/3,2-3,5; comprimento do élitro, 6,8/8,5-9,0; largura umeral, $3,2 / 3,7-4,2$.

Material-tipo. Holótipo fêmea, BRASIL, Santa Catarina: Rio Vermelho, XII.1961, Dirings (MZSP). Parátipos. BRASIL, Paraná: Guaraúna, fêmea, I.1955, [sem nome do coletor] (MZSP); Ponta Grossa, fêmea, XI.1938, Camargo col. (MZSP); macho, XII.1938, Camargo col. (MZSP).

Discussão. Bisaltes taua sp. nov. assemelha-se a $B$. subreticulatus Aurivillius, 1920 mas difere pelo pronoto sem as duas faixas acastanhadas longitudinais do meio do disco; pela presença de faixa oblíqua nos élitros desde os úmeros até o meio; pela pubescência mais longa, densa e bicolor; pelo antenômero V branco com ápice preto. Bisaltes subreticulatus tem duas faixas acastanhadas, longitudinais no meio do pronoto; os élitros não têm faixas de pubescência esbranquiçada; a pubescência é mais curta, mais rala e unicolor; o antenômero V é todo preto com estreita orla basal branca.

Distingue-se de B. brevicornis Breuning, 1939 que também apresenta faixa clara, oblíqua na metade basal dos élitros, pela pubescência densa, longa e bicolor do pronoto e pelo escutelo unicolor. Em B. brevicornis a pubescência é unicolor, amareloesbranquiçada, constituída por pêlos curtos; a faixa oblíqua da metade basal dos élitros é mais estreita e o escutelo tem pubescência amarelada no centro e preta nas bordas.

\section{Bisaltes (B.) unicolor sp. nov.}

(Fig. 3)

Tegumento avermelhado recoberto por pubescência amarelo-acastanhada; nos élitros, tegumento preto em estreita faixa sutural da base até antes do meio. Face ventral com tegumento preto. Pernas com pubescência entremeada por máculas contrastantes, pretas; tegumento dos fêmures e das metatíbias parcialmente preto. Urosternitos I-IV com faixa central, glabra.

Fronte convexa. Lobos oculares superiores tão distantes entre si quanto o sêxtuplo da largura de um lobo; lobos oculares inferiores tão longos quanto as genas. Antenas dos machos atingem o quarto apical dos élitros; tegumento avermelhado, recoberto por pubescência branco-amarelada; escapo com 


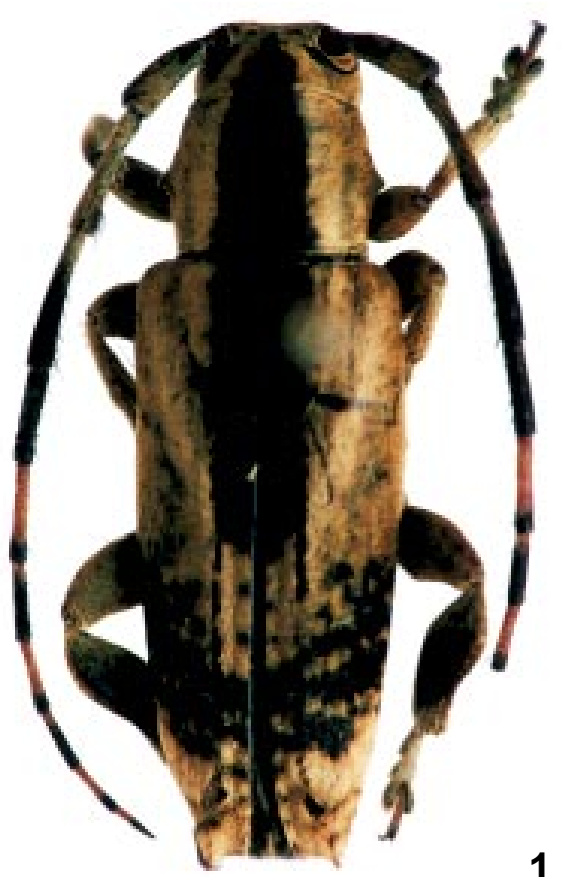

1

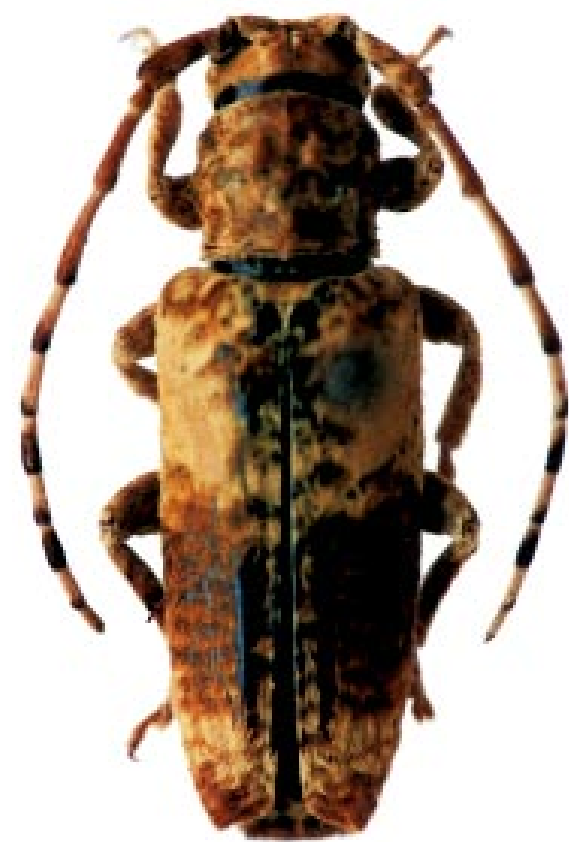

2
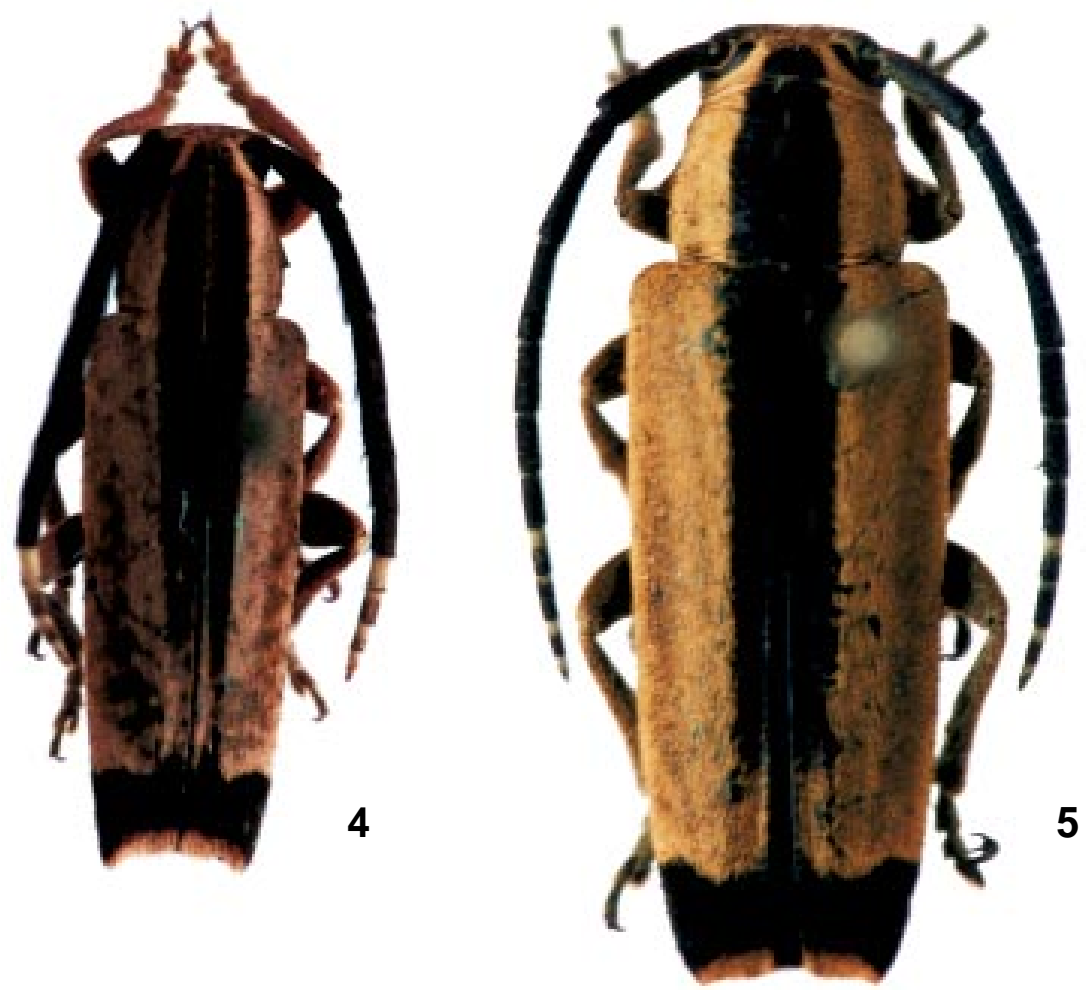

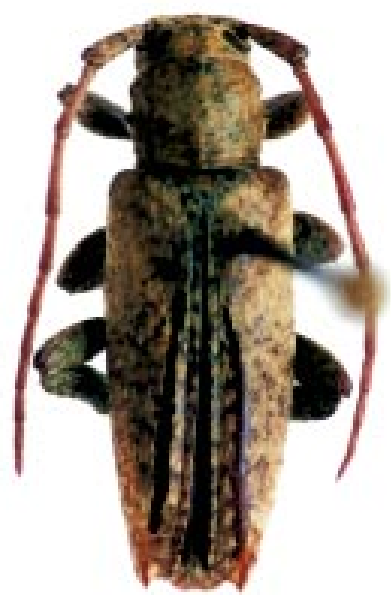

3

Figs. 1-6. 1, Bisaltes (B.) picticornis sp. nov., holótipo macho, Uyapi, Guanay, Beni, Bolívia, comprimento, 12,6 mm; 2, Bisaltes (B.) taua sp. nov., holótipo fêma, Rio Vermelho, Santa Catarina, Brasil, 12,1 mm; 3, Bisaltes (B.) unicolor sp. nov., holótipo macho, Hitao del Mundo, Pichincha, Equador, comprimento 8,3 mm; 4, Ptericoptus acuminatus, macho, Deodoro, Rio de Janeiro, Rio de Janeiro, Brasil, comprimento, 11,1 mm; 5, Ptericoptus dorsalis, fêmea, São Paulo, São Paulo, comprimento 14,3 mm; 6, Ptericoptus corumbaensis, holótipo macho, Corumbá, Mato Grosso do Sul, Brasil, comprimento 10,8 mm. 
algumas áreas glabras contrastantes. Antenômero IV mais longo do que o III; V-XI com comprimentos gradualmente decrescentes. Protórax mais largo do que longo, com espinho lateral evidente.

Élitros com elevação longitudinal paralela à sutura desde antes do meio até o ápice; extremidades com espinho longo no lado externo; setas elitrais amareladas. Metatíbias dos machos fortemente engrossadas.

Dimensões, em mm, macho. Comprimento do protórax, 1,7; maior largura do protórax, 2,2; comprimento do élitro, 6,3; largura umeral, 2,8.

Material-tipo. Holótipo macho, EQUADOR, Pichincha: Hitao del Mundo, 3.V.1984, R. Haswell col. (MZSP).

Discussão. Bisaltes unicolor sp. nov. apresenta pubescência amarelada, unicolor, apenas entremeada por manchas escuras no escapo e nas pernas, coloração rara nas espécies do gênero. Nas espécies com pubescência corporal uniforme, as antenas geralmente são bicolores e têm artículos acastanhados ou pretos entremeados àqueles providos por pubescência clara.

A faixa glabra do centro do abdômen de B. unicolor não foi mencionada por Breuning (1971) para nenhuma espécie de Bisaltes e não pudemos comprovar a sua existência nos dispositivos dos tipos, pois as fotos são em vista dorsal.

\section{Bisaltes (Craspedocerus) pictus Breuning, 1940}

Bisaltes pictus Breuning, 1940: 43

Bisaltes (Bisaltes) pictus; Breuning, 1960: 178 (cat.); Monné, 1994: 22 (cat.).

Bisaltes (Craspedocerus) pictus apresenta os antenômeros III a VII engrossados e densamente pubescentes no lado interno, conforme constatado pelo exame do diapositivo do holótipo macho, depositado no NHRM. Portanto, sua posição correta é no subgênero Craspedocerus.

\section{Ptericoptus acuminatus (Fabricius, 1801)}

$$
\text { (Fig. 4) }
$$

Saperda acuminata Fabricius, 1801:323.

Ptericoptus acuminatus; Gemminger \& Harold, 1873: 3101 (cat.); Monné, 1994: 18 (cat.).

Saperda dentipennis Latreille, 1811: 56, est.3, fig.11.

Colobothea dentipennis; Gemminger \& Harold, 1873: 3172 (cat.).

Ptericoptus dentipennis; Aurivillius, 1922:295 (cat.)

Ptericoptus hybridus hybridus Breuning, 1939: 233; Monné, 1994: 19 (cat.). Syn. nov.

A identificação de $P$. acuminatus foi feita através do exame de três cótipos fotografados por J. S. Moure; o primeiro com procedência vaga "América meridional” e os outros dois sem dados de procedência. Aparentemente, os três pertencem à mesma espécie.

No primeiro cótipo, o tegumento é castanho; avermelhado nas pernas e na face ventral. Pubescência róseo-clara, exceto: mancha acastanhada no vértice, continuada pelo meio do pronoto e pela região sutural dos élitros até o terço posterior.
Antenas atingem o terço apical dos élitros; flagelômeros engrossados (o ápice do antenômero III tão largo quanto o do escapo); recobertas por pubescência castanha exceto os artículos VII, X e XI que são revestidos por pubescência esbranquiçada, menos na ponta e o IX circundado, na base, por anel de pubescência branca. Faixa de pubescência castanha que se inicia atrás dos olhos e vai até a região subumeral, indistintamente prolongada pelos élitros. Uma faixa transversal, ante-apical preta cuja borda anterior é nitidamente bissinuosa. Manchas laterais nos urosternitos II a V e borda apical do urosternito $\mathrm{V}$ com pubescência preta.

Dimensões, em mm, macho. Comprimento do protórax, 2,4; maior largura do protórax, 2,8; comprimento do élitro, 8,5; largura umeral, 3,3.

Material examinado. BRASIL, Rio de Janeiro: Rio de Janeiro (Deodoro), macho, 6.X.1938, W. Zikán col. (MZSP).

Discussão. Saperda dentipennis Latreille, 1811 foi originalmente figurada, mas como essa figura não é elucidativa por não termos tido acesso ao material-tipo ou ao diapositivo do tipo, é mantida na sinonímia de Ptericoptus acuminatus.

Ptericoptus dorsalis Audinet-Serville, 1835 não é sinônima de Ptericoptus acuminatus e é revalidada. Saperda vitta Newman, 1838 sai da sinonímia de $P$. acuminatus e passa à sinonímia de $P$. dorsalis.

Ptericoptus hybridus Breuning, 1939, foi originalmente descrita com base em duas subespécies: P. h. hybridus da Bahia, Brasil e $P$. hybridus meridionalis do Paraguai. O exame do holótipo de $P$. h. hybridus, por meio do diapositivo feito por $\mathrm{J}$. S. Moure no BMNH, revelou sua sinonímia com P. acuminatus que, provavelmente, Breuning identificou erroneamente. Observamos, também, que o exemplar figurado por BREUnING (1971: 330, fig. 15) não é coespecífico com o holótipo de $P$. hybridus. A outra subespécie, $P$. hybridus meridionalis, pode pertencer a uma espécie diferente e, certamente, não é coespecífica com $P$. h. hybridus (= P. acuminatus).

Ptericoptus acuminatus $\mathrm{m}$. reductus Breuning, 1971 (nomen nudum), segundo o exame do diaposivo do holótipo (MNHN), trata-se de uma variação de $P$. dorsalis e, talvez, possa constituir-se em uma subespécie sem faixa escura, transversal, ante-apical nos élitros. A forma reductus foi descrita de Jataí, Goiás e $P$. dorsalis ocorre na Mata Atlântica.

\section{Ptericoptus dorsalis Audinet-Serville, 1835, revalidada} (Fig.5)

Ptericoptus dorsalis Audinet-Serville, 1835: 61; Monné, 1994: 18 (cat., in syn. de $P$. acuminatus).

Saperda vitta Newman, 1838: 395; Monné, 1994: 18 (cat., in syn. de $P$. acuminatus). Syn. nov.

? Ptericoptus acuminatus m. reductus Breuning, 1971: 271; Monné, 1994: 18 (cat., in syn. de P. acuminatus) (nomen nudum).

Antenas pretas até o antenômero VII; os artículos VIII, X e XI com a metade basal recoberta por pubescência branca e o anel basal do IX também branco. Escapo recoberto por pubescência branca ou essa pubescência restrita ao lado 
inferior. Face ventral dos antenômeros III a VII com pubescência esbranquiçada.

Cabeça revestida por pubescência amarelada com uma faixa estreita de pubescência acastanhada entre os tubérculos anteníferos. Região posterior aos lobos oculares com uma faixa de pubescência mais acastanhada que também percorre os lados do protórax. Uma mancha preta no occipício continuada pela faixa longitudinal no meio do pronoto e nos élitros até o terço apical; essa faixa, principalmente nos élitros, é coberta por pubescência castanha. Protórax e élitros revestidos (exceto as faixas) por pubescência amarelada. Faixa preta ante-apical mais ou menos sinuosa na borda anterior. Pernas e face ventral do corpo revestidas por pubescência amarelada; lados dos urosternitos III a V com manchas pretas. Borda apical do último urosternito preta.

Procedências do material examinado (MZSP). BRASIL, Pará: Óbidos. Ceará: Barbalha. Paraíba: Areias. Bahia: Salvador. Minas Gerais: Mar de Espanha, Santa Bárbara (Serra do Caraça, Fazenda Engenho).São Paulo: Assis, Cotia, Diadema, Guarulhos, Santo André, São Paulo (Ipiranga, Jabaquara, Santo Amaro). Mato Grosso: Rosário Oeste. Mato Grosso do Sul: Rio Paraná.

Discussão. O exame dos diapositivos dos holótipos de $P$. dorsalis e S. vitta, feitos por J. S. Moure no BMNH, revelou que essas espécies são sinônimas e não são coespecíficas com $P$. acuminatus. A diferença entre $P$. dorsalis e $P$. vitta restringe-se à pubescência amarelada das antenas; em $P$. vitta, recobre a face ventral do escapo e o lado ventral dos antenômeros; em P. dorsalis, reveste todo o escapo e a base de todos os antenômeros nas faces dorsal e ventral.

Ptericoptus dorsalis difere de P. acuminatus pela pubescência corporal amarelada, pelo escapo com pubescência branca, pelos antenômeros menos engrossados e até o VII com pubescência branca na face inferior; pela faixa preta anteapical dos élitros com a margem anterior menos sinuosa, além do aspecto geral mais robusto.

\section{Ptericoptus corumbaensis sp. nov.}

(Fig. 6)

Cabeça revestida por pubescência branco-amarelada com mancha de pubescência castanha no occipício; faixa castanha atrás dos lobos oculares. Antenas atingem o meio dos élitros; flagelômeros basais intumescidos; antenômeros revestidos inteiramente por pubescência escura exceto o X e o XI com estreito anel basal de pubescência branca. Protórax com pubescência amarelada e uma faixa larga, acastanhada, no meio do dorso, (em continuação com a do occipício) e uma faixa abaixo do espinho lateral. Élitros com pubescência amarelada; faixa sutural de pubescência acastanhada da base ao terço apical; outra faixa longitudinal, menos distinta, dos úmeros até a faixa preta ante apical; esta faixa com a borda anterior acentuadamente sinuosa. Esternos torácicos revestidos por pubescência branco-amarelada. Metacoxas, primeiro urosternito e metade basal dos metafêmures com pubescência acastanhada. Lados do urosternito IV com mancha preta; urosternito $\mathrm{V}$ inteiramente preto.

Dimensões, em mm, macho. Comprimento do protórax, 2,4; maior largura do protórax, 2,9; comprimento do élitro, 8,5; largura umeral, 3,3.

Material-tipo. Holótipo macho, BRASIL, Mato Grosso do Sul: Corumbá, XI.1917, E. Garbe col. (MZSP).

Discussão. Ptericoptus corumbaensis sp. nov. difere de $P$. acuminatus pela pubescência corporal amarelada, pelas antenas unicolores e mais curtas e metacoxas, urosternito I e base dos metafêmures revestidos por pubescência acastanhada.

Agradecimentos. Ao Dr. Renato C. Marinoni, Universidade Federal do Paraná, pelo empréstimo dos diapositivos dos tipos; aos colegas Sonia A. Casari e Antonio dos Santos Silva pelo auxílio na execução das fotografias.

\section{REFERÊNCIAS}

Audinet-Serville, J. G. 1835. Nouvelle classification de la famille des longicornes. (suite). Annales de la Societé Entomologique de France (1)4: 5-100.

Aurivillius, C. 1922. Coleopterorum Catalogus, pars 73, Cerambycidae: Lamiinae. Berlin, W. Junk, 322 p.

Breuning, S. 1939. Novae species Cerambycidarum. VII. Festschrift 60 Geburtstag E. Strand 5: 144-290.

Breuning, S. 1940. Novae species Cerambycidarum. VIII. Folia Zoologica et Hydrobiologica 10: 37-85.

Breuning, S. 1960. Catalogue des Lamiaires du Monde (Col., Cerambycidae). 3 Lief. Tutzing bei München, Mus. G. Frey, p. 109-182.

Breuning, S. 1971. Révision des espèces américaines de la tribue des Apomecynini Lac. (Coleoptera, Cerambycidae). Entomologische Abhandlungen Staatliches Museum für Tierkunde in Dresden 37(3): 209-235.

FABRICIUS, J. C. 1801. Systema eleutheratorum secundum ordines, genera, species: adiectis synonymis, locis, observationibus, descriptionibus. Kiliae, Academici Novi, 2: $687 \mathrm{p}$.

Gemminger, M. \& E. Harold. 1873. Catalogus Coleopterorum hucusque descriptorum synonymicus et systematicus. Monachii, 10: 2989-3232.

LATREILLE, P. A. 1811. Insectes de l’Amérique équinoxiale recueillis pendant le voyage de MM de Humboldt et Bonpland. In: Recueil d'observations de zoologie et d'anatomie comparée faites dans l'Océan Atlantique, dans l'interieur du nouveau continent et dans l'Amerique du Sud pendant les années 1799, 1800, 1801, 1802 et 1803. Paris, 2: 9-64.

MonnÉ, M. A. 1994. Catalogue of the Cerambycidae (Coleoptera) of the Western Hemisphere. Part XIV. Subfamily Lamiinae: Tribes Apomecynini, Agapanthiini and Onocephalini. São Paulo, Sociedade Brasileira de Entomologia, 72 p.

Newman, E. 1838. Entomological notes. Entomological Magazin 5: 372-402. 